\title{
Karakteristik dan Kualitas Hidup Pasien Penyakit Parkinson dengan Probabel Gangguan Perilaku Tidur Fase Gerak Mata Cepat di Manado
}

\author{
Grisheila M. Koleangan ${ }^{1}$, Arthur H. P. Mawuntu², Mieke A. H. N. Kembuan
}

\author{
${ }^{1}$ Program Studi Pendidikan Dokter Fakultas Kedokteran Universitas Sam Ratulangi Manado \\ ${ }^{2}$ Bagian/KSM Neurologi Fakultas Kedokteran Universitas Sam Ratulangi/RSUP Prof. Dr. \\ R. D. Kandou Manado \\ Email: grisheilamaria@gmail.com
}

\begin{abstract}
Rapid eye movement sleep behavior disorder (RBD) often occurs in patients with Parkinson's disease (PD) and it could reduce their quality of life (QoL). This study was aimed to obtain the characteristics and QoL of PD patients with pRBD in Manado. This was a descriptive study with a cross-sectional design. Subjects were PD patients with pRBD at Prof. Dr. R. D. Kandou Hospital from October to November 2019. The QoL was measured by using the SF-36 QoL questionnaire. The results obtained 48 eligible subjects. Male patients were more common than females (52.1\% vs $47.9 \%)$. Most of the subjects were 60-69 years (54.1\%), had senior high school and junior high school education (each of 29.1\%), and unemployed (41.7\%). Moreover, $62.5 \%$ of patients had been diagnosed as PD since 1-5 years ago. The mean score of the physical and mental component of the subjects were 46.5 and 60.8 subsequently. In conclusion, the majority of patients with Parkinson's disease and pRBD were 60-69 years, senior or junior high school educated, unemployed, and had been diagnosed as PD since 1-5 years ago. Their quality of life in physical component was below norm-based score but in mental component was still good.
\end{abstract}

Keywords: Parkinson's disease, probable RBD, quality of life, SF-36

\begin{abstract}
Abstrak: Gangguan perilaku tidur fase gerak mata cepat (rapid eye movement sleep behaviour disorder/RBD) sering terjadi pada pasien penyakit Parkinson (PD) yang mungkin menurunkan kualitas hidup mereka. Penelitian ini bertujuan untuk mengetahui karakteristik dan kualitas hidup pasien PD dengan probabel RBD (pRBD) di Manado. Jenis penelitian ialah deskriptif dengan desain potong lintang terhadap pasien PD dengan pRBD yang datang ke RSUP Prof. Dr. R. D. Kandou Manado bulan Oktober-November 2019. Kualitas hidup diukur menggunakan kuesioner kualitas hidup SF-36. Hasil penelitian mendapatkan 48 pasien yang memenuhi kriteria penelitian. Pasien berjenis kelamin laki-laki lebih banyak daripada perempuan $(52,1 \%$ vs $47,9 \%)$. Sebagian besar pasien berada pada kelompok usia 60-69 tahun $(54,1 \%)$, tingkat pendidikan terakhir SMA/Sederajat dan SMP sama banyak $(29,1 \%)$, dan tidak bekerja (41,7\%). Sebanyak 62,5\% subjek telah terdiagnosis PD sejak 1-5 tahun sebelumnya. Skor rerata komponen fisik dan komponen mental kualitas hidup SF-36 ialah 46,5 dan 60,8. Simpulan penelitian ini ialah mayoritas pasien penyakit Parkinson dengan pRBD berusia 60-69 tahun, pendidikan SMA/sederajat atau SMP, tidak bekerja, dan telah terdiagnosis PD sejak 1-5 tahun sebelumnya. Kualitas hidup pasien penyakit Parkinson dengan pRBD pada komponen fisik secara umum berada di bawah skor normatif tetapi komponen mental masih baik.
\end{abstract}

Kata kunci: penyakit Parkinson, probabel RBD, kualitas hidup, SF-36

\section{PENDAHULUAN}

Gangguan tidur adalah faktor penentu status kesehatan yang kurang diperhatikan.
Tiga keluhan klinis paling umum yang terkait dengan tidur yaitu hipersomnia, insomnia, dan perilaku atau kejadian tidak 
biasa pada malam hari (parasomnia). ${ }^{1}$ Gangguan perilaku tidur fase gerak mata cepat (rapid eye movement sleep behaviour disorder/RBD) adalah salah satu dari parasomnia utama. Gejala subklinis dari RBD sering dikaitkan dengan penyakit Parkinson (Parkinson's disease/PD). ${ }^{2}$

Meskipun patofisiologi yang tepat masih belum jelas, RBD terjadi lebih sering pada pasien dengan penyakit neurodegeneratif daripada populasi umum. Pada 457 pasien PD dengan gangguan tidur, $46 \%$ didiagnosis RBD. ${ }^{3}$ Diagnosis definit RBD memerlukan pemeriksaan polisomnografi. Namun demikian diagnosis probabel RBD (pRBD) dapat dibuat menggunakan beberapa metode seperti melihat skor pada kuesioner yang didesain khusus untuk mendeteksi adanya RBD. ${ }^{4}$ Kuesioner penyaring gangguan perilaku tidur REM (RBDSQ) merupakan kuesioner mandiri bagi pasien dan memiliki 10 pertanyaan (skor total maksimum 13 poin) dengan cutoff diagnosis probabel RBD $>5$. Validasi linguistik RBDSQ ke dalam Bahasa Indonesia telah dilakukan oleh Anggreani et al (2019). ${ }^{5}$ Di tempat-tempat yang tidak memiliki polisomnografi seperti di Manado, diagnosis $\mathrm{pRBD}$ mungkin yang akan paling banyak dibuat.

Sejauh pengetahuan penulis, belum ada data karakteristik pasien PD dengan pRBD di Manado dan informasi mengenai hal ini di Indonesia juga masih terbatas. Oleh karena itu penulis tertarik untuk mengetahui karakteristik dan kualitas hidup PD dengan pRBD di Manado.

\section{METODE PENELITIAN}

Penelitian ini dilakukan di Poliklinik Neurologi RSUP Prof. Dr. R.D. Kandou Manado (RS RDK) selama bulan OktoberNovember 2019. Jenis penelitian ialah deskriptif dengan desain potong lintang Kriteria inklusi ialah pasien yang sudah terdiagnosis PD, mendapatkan skor RBDSQ $>5$ (sesuai dengan pRBD), mampu membaca dan menjawab kuesioner yang diberikan atau, bila tidak mampu, didampingi pendamping yang dapat membaca dan menjawab kuesioner yang diberikan, serta subjek dan pendamping dapat berbahasa Indonesia. Subjek yang tidak bersedia mengikuti penelitian tidak dimasukkan dalam penelitian.

RBDSQ adalah instrumen yang menilai perilaku tidur subjek dengan pertanyaan singkat yang harus dijawab dengan "ya" atau "tidak" berisi 10 pertanyaan. Pertanyaan pertama hingga keempat membahas frekuensi dan konten mimpi dan hubungannya dengan gerakan nokturnal dan tingkah laku. Pertanyaan kelima tentang cedera diri dan cedera pasangan tidur. Pertanyaan keenam terdiri dari empat bagian yang menilai perilaku motorik malam hari secara lebih spesifik, misalnya gerakan tungkai tiba-tiba, gerakan yang rumit, atau benda tidur yang jatuh. Pertanyaan ketujuh dan kedelapan berhubungan dengan terbangun di malam hari. Pertanyaan kesembilan berfokus pada terganggunya tidur secara umum dan pertanyaan ke sepuluh adanya gangguan neurologis. Variabel-variabel yang diteliti mencakup usia, jenis kelamin, tingkat pendidikan, pekerjaan, lama terdiagnosis PD, skor RBDSQ Indonesia, serta nilai kuesioner kualitas hidup Short Form-36 (SF-36).

Usia diklasifikasikan berdasarkan penelitian yang dilakukan Pagano et $\mathrm{al}^{6}$ pada pasien penyakit Parkinson dengan pembagian kelompok usia: $<50$ tahun, 50-59 tahun, 60-69 tahun, dan $\geq 70$ tahun. Jenis pekerjaan didasarkan atas Klasifikasi Baku Jabatan Indonesia (KBJI) 2014. KBJI disusun berdasarkan International Standard Classification of Occupations (ISCO) 2008 revisi III yang merupakan revisi dari ISCO 1988. ${ }^{7}$

Berdasarkan Badan Pusat Statistik ${ }^{8}$ konsep bekerja adalah kegiatan ekonomi yang dilakukan oleh seseorang dengan maksud memperoleh atau membantu memperoleh pendapatan atau keuntungan, paling sedikit 1 jam (tidak terputus) dalam seminggu yang lalu. Mengurus rumah tangga adalah kegiatan seseorang yang mengurus rumah tangga tanpa mendapatkan upah, misalnya ibu rumah tangga dan anaknya yang membantu mengurus rumah tangga, sehingga tidak termasuk dalam kelompok bekerja. Jenis pekerjaan/jabatan adalah macam peker- 
jaan yang dilakukan oleh seseorang atau ditugaskan kepada seseorang yang sedang bekerja atau yang sementara tidak bekerja.

Pemeriksaan kualitas hidup menggunakan kuesioner SF-36 yang sudah divalidasi di Indonesia. Kuesioner Kualitas Hidup SF36 Indonesia terdiri dari 36 pertanyaan dan terdiri dari delapan domain yang menghasilkan dua komponen besar: kesehatan fisik dan mental. Komponen kesehatan fisik meliputi empat domain, yaitu fungsi fisik (10 pertanyaan), keterbatasan fisik (4 pertanyaan), nyeri tubuh (2 pertanyaan), dan kesehatan secara umum (6 pertanyaan). Ukuran kesehatan mental terdiri dari vitalitas (4 pertanyaan), fungsi sosial (2 pertanyaan), keterbatasan emosional (3 pertanyaan), dan kesehatan mental (5 pertanyaan). Kuesioner SF-36 memiliki format penilaian waktu standar 4 minggu atau akut (1 minggu). ${ }^{9,10}$

Metode skoring dari setiap pertanyaan dalam kuesioner berdasarkan tabel-tabel berikut dengan dua langkah, yaitu: ${ }^{11} 1$ ) Setiap jawaban pertanyaan diberikan skor 2) Pertanyaan dari masing-masing domain dirata-ratakan untuk membuat delapan skor utama. Pertanyaan yang tidak dijawab (dibiarkan kosong) tidak diperhitungkan saat menghitung skor utama. Oleh karena itu, skor utama mewakili semua pertanyaan yang dijawab oleh responden.

Panduan Manual SF-36 merekomendasikan untuk menggunakan norm based scores (NBS) atau skor rata-rata normatif dibandingkan menggunakan skor 0-100 untuk menyederhanakan interpretasi data. Skor rata-rata normatif populasi umum dapat dibuat ke dalam algoritma skoring sehingga dokter dan peneliti tidak perlu mengingat skor normatif untuk masingmasing domain. ${ }^{12}$

Dengan adanya skor rerata normatif, setiap domain diberi skor rerata yang sama, yaitu 50 dan standar deviasi yang sama, yaitu 10. Setiap skor domain di bawah 50, maka status kesehatan dikatakan berada di bawah rerata begitu pula sebaliknya. ${ }^{13}$

Pada penelitian ini digunakan skor rerata normatif 50 berdasarkan penelitian yang telah dilakukan oleh Ware et $\mathrm{al}^{13}$ pada populasi umum di Amerika karena sejauh tinjauan penulis belum ada penelitian untuk mencari skor rerata normatif pada populasi umum di Indonesia

\section{HASIL PENELITIAN}

Tabel 1 memperlihatkan karakteristik dari 48 subjek yang memenuhi kriteria penelitian. Jumlah subyek berdasarkan jenis kelamin tidak banyak berbeda yaitu 25 laki-laki $(52,1 \%)$ dan 23 perempuan $(47,9 \%)$. Sebagian besar subyek berusia 60-69 tahun, pendidikan SMA/sederajat atau SMP, tidak bekerja, dan telah terdiagnosis PD sejak 1-5 tahun sebelumnya.

Tabel 1. Distribusi subjek penelitian

\begin{tabular}{|c|c|c|}
\hline Variabel & $\mathbf{n}$ & $\%$ \\
\hline \multicolumn{3}{|l|}{ Jenis kelamin } \\
\hline Laki- laki & 25 & 52,1 \\
\hline Perempuan & 23 & 47,9 \\
\hline \multicolumn{3}{|l|}{ Usia (tahun) } \\
\hline$<50$ & 2 & 4,16 \\
\hline $50-59$ & 8 & 16,66 \\
\hline $60-69$ & 26 & 54,16 \\
\hline $70-80$ & 12 & 25 \\
\hline \multicolumn{3}{|l|}{ Tingkat pendidikan } \\
\hline $\mathrm{SD}$ & 9 & 18,75 \\
\hline SMP & 14 & 29,16 \\
\hline SMA/Sederajat & 14 & 29,16 \\
\hline Diploma-Sarjana & 11 & 22.91 \\
\hline \multicolumn{3}{|l|}{ Pekerjaan } \\
\hline Petani & 5 & 10,41 \\
\hline Supir & 2 & 4,16 \\
\hline Swasta & 3 & 6,25 \\
\hline Tukang & 1 & 2,08 \\
\hline Guru & 1 & 2,08 \\
\hline Pensiunan & 16 & 33,33 \\
\hline Tidak bekerja & 20 & 41,66 \\
\hline \multicolumn{3}{|l|}{ Terdiagnosis PD } \\
\hline$<1$ tahun & 6 & 12,5 \\
\hline $1-5$ tahun & 30 & 62,5 \\
\hline 6-10 Tahun & 7 & 14,58 \\
\hline$>10$ tahun & 5 & 10,41 \\
\hline
\end{tabular}

Keterangan: $\mathrm{SD}=$ Sekolah Dasar; $\mathrm{SMP}=$ Sekolah Menengah Pertama; SMA = Sekolah Menengah Atas; $\mathrm{PD}=$ Parkinson's Disease 
Tabel 2 menunjukkan sebaran skor RBDSQ versi Indonesia pada subjek. Terlihat bahwa paling banyak subjek memiliki skor RBDSQ 6 atau satu poin di atas nilai cut-off.

Tabel 2. Sebaran skor RBDSQ pada subjek penelitian.

\begin{tabular}{ccc}
\hline $\begin{array}{c}\text { Skor Total } \\
\text { RBDSQ }\end{array}$ & $\mathbf{n}$ & $\boldsymbol{\%}$ \\
\hline 5 & 7 & 14,58 \\
6 & 10 & 20,83 \\
7 & 9 & 18,75 \\
8 & 9 & 18,75 \\
9 & 5 & 10,41 \\
10 & 2 & 4,16 \\
11 & 4 & 8,33 \\
12 & 2 & 4,16 \\
\hline
\end{tabular}

Tabel 3 dan Tabel 4 memperlihatkan hasil pemeriksaan kualitas hidup subjek penelitian.

Tabel 3. Rerata kualitas hidup subjek penelitian pada setiap domain kualitas hidup.

\begin{tabular}{cc}
\hline Domain & Rerata \\
\hline Skor fungsi fisik (0-100) & 47,5 \\
Skor keterbatasan fisik (0-100) & 27,0 \\
Skor nyeri tubuh (0-100) & 67,9 \\
Skor kesehatan secara umum (0- & 43,4 \\
100) & 57,8 \\
Skor vitalitas (0-100) & 80,2 \\
Skor fungsi sosial (0-100) & 38,1 \\
Skor keterbatasan emosional & (0-100) \\
Skor kesehatan mental (0-100) & 67,0 \\
\hline
\end{tabular}

Tabel 4. Rerata skor kualitas hidup subjek penelitian pada setiap komponen.

\begin{tabular}{cc}
\hline Komponen & Rerata \\
\hline Skor komponen fisik (0-100) & 46,5 \\
Skor komponen mental (0-100) & 60,8 \\
\hline
\end{tabular}

\section{BAHASAN}

Pada penelitian ini proporsi pasien laki-laki dan perempuan tidak begitu berbeda. Hal ini sesuai dengan penelitian yang dilakukan oleh Bjornara et $\mathrm{al}^{14}$ bahwa tidak ditemukan perbedaan bermakna terhadap jumlah pasien PD dengan pRBD laki-laki dan perempuan. Namun penelitian yang dilakukan oleh Miller et $\mathrm{al}^{15}$ dan Kumanogo et $\mathrm{al}^{16}$ pada pasien PD mendapatkan pasien laki-laki lebih banyak dari perempuan. Alasan dominasi laki-laki tidak diketahui, tetapi pengaruh hormon androgen pada laki-laki dipertimbangkan dan efek estrogen pada neuron dan jalur dopaminergik di otak mungkin berpengaruh.

Usia terbanyak yaitu 60-69 tahun dengan jumlah 26 orang $(54,1 \%)$. Hal ini sesuai dengan penelitian yang dilakukan oleh Silitonga ${ }^{17}$ pada 31 pasien PD yang mendapatkan rerata usia 61 tahun. Yoritaka et $\mathrm{al}^{18}$ melakukan penelitian pada 150 pasien PD, dan diagnosis RBD ditemukan pada pasien usia di atas 65 tahun. Penyakit Parkinson dikenal sebagai penyakit usia lanjut karena paling sering didiagnosis pada orang di atas usia 60 tahun. ${ }^{19}$

Berdasarkan tingkat pendidikan, didapatkan pendidikan SMA/sederajat dan SMP memiliki jumlah terbanyak yaitu, 14 orang $(29,1 \%)$. Hasil yang didapatkan selaras dengan penelitian yang dilakukan oleh Silitonga ${ }^{17}$ pada pasien PD dengan jumlah terbanyak berada di pendidikan SMA/sederajat yaitu 11 pasien $(35,5 \%)$.

Berdasarkan pekerjaan, didapatkan sebanyak 20 orang $(41,66 \%)$ pasien sudah tidak bekerja. Tarukbua et al ${ }^{20}$ meneliti 31 pasien PD di Poliklinik Saraf RSUP Prof. Dr. R. D. Kandou Manado dan mendapatkan sebagian besar pasien tidak lagi bekerja. Akibat dari perjalanan penyakit yang dialami pasien terkait dengan gerakan, termasuk tremor, kekakuan, lambatnya gerakan dan sulitnya berjalan memengaruhi aktivitas sehari-sehari dalam bekerja. ${ }^{21}$

Berdasarkan hasil penelitian sebanyak 30 orang $(62,5 \%)$ terdiagnosis PD sejak rentang waktu 1-5 tahun yang lalu. Penelitian yang dilakukan oleh Chan et $\mathrm{al}^{22}$ mendapatkan bahwa secara keseluruhan pasien RBD idiopatik dikonversi menjadi PD setelah 5 tahun. Gomutbutra et $\mathrm{al}^{23}$ melakukan penelitian pada 68 pasien PD dengan probabel RBD dan menemukan onset rerata dari probabel RBD sebelum didiagnosis PD ialah 5 tahun (rentang waktu 0-11 tahun). 
Hasil penelitian ini menunjukkan bahwa 4 dari 8 domain kualitas hidup memiliki skor rerata di bawah skor rerata normatif yaitu 50. Skor rerata normatif diperoleh berdasarkan penelitian yang telah dilakukan oleh Ware et $\mathrm{al}^{24}$ pada populasi umum di Amerika dan sudah pernah digunakan pada beberapa penelitian kualitas hidup menggunakan SF-36 Indonesia. ${ }^{25}$

Skor rerata kualitas hidup pasien PD dengan diagnosis probabel RBD yang dinyatakan rendah ialah pada domain fungsi fisik $(47,5)$, keterbatasan fisik $(27,0)$, kesehatan secara umum $(43,4)$, dan keterbatasan emosional $(38,1)$. Hal ini sejalan dengan penelitian yang dilakukan oleh Rolinski et $\mathrm{al}^{26}$ pada 475 pasien PD dengan diagnosis pRBD menggunakan REM Sleep Behavior Disorder Screening Questionnaire (RBDSQ) yang melaporkan penurunan nilai di setiap domain kuesioner Euro Quality of Life (EQ-5D) dan skor kesehatan yang rendah secara keseluruhan.

Pada domain fungsi fisik didapatkan hasil sedikit rendah di bawah rerata normatif. Berdasarkan Ware et al, ${ }^{13}$ skor yang rendah memiliki keterbatasan dalam melakukan semua aktivitas fisik, termasuk mandi atau ganti pakaian. Domain keterbatasan fisik $(27,0)$, terdapat masalah dengan pekerjaan atau aktivitas harian sebagai dampak dari kesehatan fisik. Domain kesehatan secara umum $(43,4)$ menjelaskan bahwa pasien mengevaluasi kesehatan pribadinya tidak baik dan percaya kemungkinan kondisinya akan bertambah buruk. Domain keterbatasan emosional $(38,1)$ menyatakan terdapat masalah dengan pekerjaan atau aktivitas harian sebagai dampak masalah emosional.

Selanjutnya domain nyeri tubuh, vitalitas, fungsi sosial dan kesehatan mental berada di atas rerata normatif. Domain nyeri tubuh $(67,9)$ sebagian besar subyek tidak mengeluh nyeri atau memiliki keterbatasan karena rasa sakit. Domain vitalitas $(57,8)$, subjek masih merasa semangat dan penuh energi setiap waktu. Domain fungsi sosial $(80,2)$, subjek masih dapat melakukan kegiatan sosial yang normal dan tanpa gangguan fisik atau masalah emosional. Domain kesehatan mental $(67,0)$, sebagian besar subjek masih merasa damai, bahagia, dan tenang sepanjang waktu. ${ }^{13}$

Penelitian yang dilakukan Neikrug et $\mathrm{al}^{27}$ menunjukkan bahwa pada PD dengan RBD dikaitkan dengan peningkatan nonmotor symptoms (NMS) atau gejala nonmotor dibandingkan dengan PD tanpa RBD. Telah ditemukan bahwa pada PD dengan RBD dikaitkan dengan peningkatan gejala depresi, gangguan tidur, kelelahan, disfungsi penciuman, dan gejala hipotensi ortostatik. Hal ini mendukung penelitianpenelitian sebelumnya yang menunjukkan bahwa RBD terkait dengan peningkatan frekuensi dan tingkat keparahan gangguan non-motorik sehingga dapat memperburuk kualitas hidup.

Kualitas hidup seseorang terbagi menjadi dua komponen penilaian yaitu komponen fisik dan komponen mental. ${ }^{13}$

Skor rerata komponen fisik kualitas hidup pasien Penyakit Parkinson dengan probabel RBD yaitu 46,5 berada di bawah skor rerata normatif. Subjek memiliki keterbatasan dalam perawatan diri, fisik, sosial, dan keterbatasan kegiatan, sering merasa lelah, peringkat kesehatan "buruk". Namun skor rerata komponen mental, yaitu 60,8 masih berada di atas skor rerata normatif. Hal ini masih dapat berdampak positif, kurangnya kesulitan psikologis dan keterbatasan dalam kegiatan sosial/keterbatasan aktivitas karena masalah emosional. ${ }^{13}$

Penelitian yang dilakukan Hopman et $\mathrm{al}^{28}$ menyatakan bahwa pada penyakit kronis dampak terhadap kesehatan fisik mengalami penurunan tetapi sebaliknya pada kesehatan mental tidak terjadi perubahan bermakna.

Keterbatasan penelitian ini ialah skor rerata normatif yang digunakan berdasarkan populasi umum di Amerika karena belum ada penelitian di Indonesia. Subjek penelitian terbatas pada pasien PD yang datang rawat jalan di Poliklinik Saraf RS RDK Manado, sehingga tidak bisa menjangkau pasien PD stadium lanjut yang di rawat inap ataupun yang tidak bisa ke Poli rawat jalan. 


\section{SIMPULAN}

Pasien PD dengan pRBD di Manado terbanyak berjenis kelamin laki-laki, rentang usia 60-69 tahun, tingkat pendidikan terakhir SMA/Sederajat dan SMP, serta tidak bekerja. Secara umum, kualitas hidup pasien PD dengan pRBD pada konponen fisik berada di bawah skor normatif tetapi komponen mental masih baik.

Hasil penelitian ini memperlihatkan perlunya dilakukan skrining RBD dan evaluasi kualitas hidup pada setiap pasien PD. Di masa mendatang perlu dilakukan penelitian analitik untuk meneliti lebih lanjut hubungan antara kualitas hidup dan pasien PD dengan RBD.

\section{Konflik Kepentingan}

Penulis menyatakan tidak terdapat konflik kepentingan dalam studi ini.

\section{DAFTAR PUSTAKA}

1. Mansukhani MP, Kolla BP, St. Louis EK, Morgenthaler TI. Sleep disorder. In: Kellerman RD, Rakel D, editors. Conn's Current Therapy, 2019; p. 721-36.

2. Huang J, Shen Y, Liu C. REM sleep without atonia and dream-enactment behavior in Parkinson's disease. Sleep Med. 2017; 40:137.

3. McCarter SJ, St Louis EK, Boeve BF. REM sleep behavior disorder and REM sleep without atonia as an early manifestation of degenerative neurological disease. Curr Neurol Neurosci Rep. 2012;12(2): 182-92.

4. Kolster S, Doring S, Trenkwaldder C, HeinzelGutenbrunner M, Seppi K, Poewe W, et al. Diagnostic value of the REM sleep behavior disorder screening questionnaire in Parkinson's disease. Sleep Med. 2015;16(1):186-9.

5. Anggreani R, Mawuntu AHP, Kembuan MAHN. Penerjemahan dan validasi linguistik rapid eye movement sleep behavior disorder questionnaire (RBDSQ) ke Bahasa Indonesia di RSUP Prof. Dr. R .D. Kandou: Penelitian permulaan. Sinaps. 2019; II(2).

6. Pagano G, Ferrara N, Pavese N. Age at onset and Parkinson disease phenotype. American Academy of Neurology. 2016;86(15):1400-7.
7. Klasifikasi Baku Jabatan Indonesia. Jakarta: Kementerian Ketenagakerjaan dan Badan Pusat Statistik, 2014.

8. Badan Pusat Statistik. [Online]. [cited 2020 Jan 2]. Available from: HYPERLINK https://www.bps.go.id/subject/6/tenagakerja.html.

9. Von Der Heyde R. Assessment of functional outcomes. Fundamentals of Hand Therapy. 2007;(6):98-113.

10. Stocchi F, Martinez PM, Hein. Quality of life in Parkinson's Disease - Patient, Clinical and reearch perspectives. European Neurological Review. 2014; 9(1):12-8.

11. 36-Item Short Form Survey (SF-36). RAND Corporation. 1994-2019.

12. Burholt V, Nash P. Short form 36 (SF-36) health survey questionnaire: normative data for Wales. Journal of Public Health. 2011;33(4):587-603.

13. Ware JE. SF-36 health survey update. Spine. 2001;25(24):3130-9.

14. Bjornara KA, Dietrichs E, Toft M. REM sleep behavior disorder in Parkinson's disease, is there a gender difference? Parkinsonism and Related Disorders. 2013;19:120-122.

15. Miller IN, Golomb AC. Gender differences in Parkinson's Disease: Clinical. Mov Disord. 2010;15(25):2695-703.

16. Kumanogo T, Mikami A, Suganuma N, Adachi H, Shigedo Y, Sugita Y, et al. Rapid eye movement sleep behavior disorder. Psychogeriatrics. 2001;1:26572.

17. Silitonga R. Faktor-faktor yang berhubungan dengan kualitas hidup penderita penyakit Parkinson d Poliklinik Saraf RS Dr. Kariadi [Tesis]. Semarsng: Universitas Diponegoro; 2007.

18. Yoritaka A, Ohizumi A, Tanaka S, Hattori N. Parkinson's disease with and without REM sleep behavior disorder : are there any clinical differences. European Neurology. 2009;61:164-70.

19. Downward E, Pool JJ. Parkinson's Disease.net. [Online]. 2019 [cited 2019 Dec 22]. Available from: HYPERLINKhttps://parkinsons disease. net/elderly-population/

20. Tarukbua FF, Tumewah R, Maja J. Gambaran Fungsi kognitif penderita Parkinson di Poliklinisk Saraf RSUP Prof. Dr. R. D. Kandou Manado. e-CliniC. 2016; 4(1). 
21. Opara JA, Brola W, Leonardi M, Blaszczyk B. Quality of life in Parkinson`s disease. Journal of Medicine and Life. 2012; 5(4):375-81.

22. Chan PC, Lee HH, Hong CT, Hu CJ, Wu D. REM sleep behavior disorder (RBD) in dementia with Lewy bodies (DLB). Behav Neurol. 2018;2018:9421098..

23. Gomutbutra P, Kanjanaratanakorn K, Tiyapun N. Prevalence and clinical characteristics of probable REM behavior disorder in Thai Parkinson's disease patients. Parkinson's Disease. Februari 2018. Article ID 7657191.

24. Ware JE, Kosinski M, Keller SD. SF-36 Physical and Mental Health Summary Scales - A User's Manual (5th ed). Boston, M.A: Health Assessment Lab, New England Medical Center, 1994.

25. Ningrum WAC, Hidayati T, Rahma. Kualitas hidup pasien urolithiasis pada komponen fisik dan komponen mental dengan instrumen Short Form-36 (SF36). Jurnal Care. 2016;4(3):70-77.

26. Rolinski M, Szewczyk-Krolikowski K, Tomlinson PR, Nithi K, Talbot K, BenShlomo Y, et al. REM sleep behaviour disorder is associated with worse quality of life and other non-motor features in early Parkinson's disease. J Neurol Neurosurg Psychiatry. 2014;85:560-6.

27. Avanzino JA, Neikrug AB, Liu L, Maglione JE, Natarajan L, Bloom C, et al. Parkinson's disease and REM sleep behavior disorder result in increased non-motor symptoms. Sleep Med. 2014; 15(8):959-66.

28. Hopman WM, Harrison MB, Coo H, Friedberg MH, Buchanan M. Associations between chronic disease, age, and physical and mental health status. Chronic Diseases in Canada. 2009; 29(2) 108-16. 